\title{
El vínculo: mecanismo discursivo configurador de la subjetividad
}

\author{
Jairo Acevedo Leal \\ Magíster en Lingüística Hispanoamericana \\ del Instituto Caro y Cuervo, Bogotá, Colombia. \\ Doctorando en Educación, Universidad Pedagógica Experimental \\ Libertador. \\ Núcleo Maturín, República Bolivariana de Venezuela. \\ Docente del Municipio de Barrancabermeja. \\ jacevedoleal@gmail.com
}

Artículo de reflexión recibido el 19 de febrero de 2015; aceptado el 26 de mayo de 2015.

\section{Cómo citar este artículo:}

Acevedo, J. (2015) El vínculo. Mecanismo discursivo configurador de la subjetividad. Espiral, Revista de Docencia e Investigación, 5(1), 77-92.

\section{Resumen}

El presente artículo se plantea como objetivo identificar la incidencia del lenguaje, y del vínculo que a través de él se establece, en la configuración de los sujetos educativos. Para esto se procede a interpretar cómo las relaciones sociales configuran la subjetividad y valoran su pertinencia en el proceso de formación. El lenguaje, en situaciones comunicativas concretas, asume un enfoque pragmático. Su lectura permite interpretar las historias de vida de un grupo de docentes, construidas a partir de la indagación sobre el pensar, el ser y el hacer que prefigura su existencia. La indagación metodológia de los sujetos analizados se hace al recurrir a los aportes del análisis del discurso, y asumir la descripción, el análisis y la crítica como procesos propios de una hermenéutica discursiva, que permiten identificar la configuración subjetiva en el espacio escolar. El artículo concluye señalando el vínculo que el discurso configura, como determinante del sujeto educativo que habita la escuela.

Palabras clave: vínculo, subjetividad, lenguaje, pragmática, discurso.

\section{Abstract}

This paper aims to identify the incidence of language, and the link through it is established, in shaping educational subjects. For this, we proceed to interpret how social relationships shape the subjectivity and assess their relevance in the training process. The language in specific communicative situations, takes a pragmatic approach. Reading allows to interpret the life stories of a group of teachers, built on the research about thinking, being and doing that prefigures its existence. The investigation to say, the analyzed subjects, is methodologically done by using the contributions of discourse analysis, assuming the description, analysis and criticism as processes, typical of a discursive hermeneutics, that identify the subjective configuration in the school. The article concludes by pointing out the link the speech sets, as a determinant of the educational subject that inhabits school.

Keywords: link, subjectivity, language, pragmatics, discourse.

\section{Introducción}

El presente texto tiene el propósito de develar el poder del vínculo, entendido como mecanismo discursivo, en la configuración de la subjetividad. El abordaje metodológico busca en las historias de vida de un grupo de docentes del oriente venezolano, huellas orientadoras de la construcción del sujeto educativo. La pesquisa pretende dar respuesta del "Ser" desde una episteme y una ética que problematiza la conciencia "de sí" y "para sí", siendo el vínculo humano, en contextos temporales y espaciales, el generador del sujeto educativo. Se pretende demostrar que el vínculo se instaura mediante el lenguaje, en el relacionamiento socio-cultural y natural del sujeto, y que este relacionamiento determina la configuración del sujeto docente que discurre día a día en el espacio escolar. 


\section{Metodología}

El enfoque hermenéutico, entendido como un "proceso de interpretación interdisciplinaria donde las partes son comprensibles desde el punto de vista del todo y el todo, a su vez, modifica y enriquece las partes" (Gadamer, 1973), está presente en cada instante del deseo de conocer. Metodológicamente este enfoque encara el lenguaje desde una "pragmática comunicativa" (Ramírez, 2004), lenguaje en uso que, mediante el análisis de las narrativas, develará el vínculo dominante del sujeto docente, que se evidenciará en el análisis discursivo y a su vez replicará en su contacto con el sujeto estudiante para configurar su concepción educativa.

El presente artículo es el resultado del Seminario de Profundización de la Maestría en Lingüística, titulado "Análisis de Discurso", impartido por el autor en la "Universidad Pedagógica Experimental Libertador", en Maturín, Estado Monagas de la República Bolivariana de Venezuela. El análisis discursivo se hizo tomando como base la "historia de vida" de 32 docentes en ejercicio (maestrandos en Lingüística) del Oriente venezolano, quienes de manera individual construyeron un texto a partir de las siguientes preguntas generadoras: ¿Quién soy? ¿Qué pienso? ¿Qué es lo que más ocupa mi pensamiento? ¿Qué hago? ¿Quién quisiera ser? ¿Qué persona despierta mi admiración? ¿Qué quisiera pensar y no puedo? ¿Qué quisiera hacer? ¿Quién no quisiera ser? ¿Qué no quisiera pensar? ¿Qué no quisiera hacer y me toca? ¿Quién ha incidido de manera significativa en lo que soy? ¿Cuál es la razón por la cual pienso como pienso? ¿Por qué hago lo que hago? Con estas preguntas se satisfacen dos inquietudes: que el docente maestrando tiene reflexiones sobre su condición de trabajador(a) de la educación, y que el texto que de ellas fluya sirva como corpus para el análisis discursivo que develará los vínculos que prevalecen en la configuración de la subjetividad del grupo analizado. El análisis discursivo se hace a través de la interpretación de las narrativas de los su- jetos, mediante la descripción, análisis y crítica de proposiciones orientadoras de categorías ideacionales que orientarán la determinación del posible vínculo dominante.

Lo anterior en la perspectiva de dar cumplimiento al objetivo de interpretar los vínculos del sujeto docente para comprender su "configuración subjetiva" y la pertinencia en su propósito de formación.

\section{El vínculo: acercamiento conceptual}

El siglo XIX marca el inicio del giro lingüístico hermenéutico de la filosofía, señalando que "la reflexión se orientará hacia el problema de la comprensión e interpretación de los signos y del lenguaje" (Palacio, 2013), dando como resultado que en el siglo XX se implante la hermenéutica en la filosofía.

En el presente estudio se encara el lenguaje como significante sobre el cual se acciona interpretativamente. Se insiste en que "el lenguaje en tanto medio significante, pide ser referido a la existencia, existencia reflexionada ahora a partir de los documentos de la vida -mundo cultural"- (Ricoeur, 2008). Asimismo, concebimos el acto interpretativo como la acción-reflexión del sujeto enunciador en discursivización con su interlocutor sobre un enunciado; como lo señala Gadamer: "interpretar significa aportar los propios conceptos previos con el fin de que la referencia del texto se haga realmente lenguaje para nosotros" (1973). Es decir, que el sentido se genere en el diálogo de horizontes.

El carácter interpretativo, fundamento hermenéutico de la presente investigación, reconoce en el signo todo el sentido que se actualiza y formaliza mediante el acto de discursivización. Se observa como "el lenguaje -signo- (ausencia) se añade a la naturaleza (presencia) y la suple, la difiere uniéndosele" (Derrida, 1986).

Es en la enunciación discursiva donde se encuentra el sentido de lo dicho y donde se organizan los entramados socioculturales que 


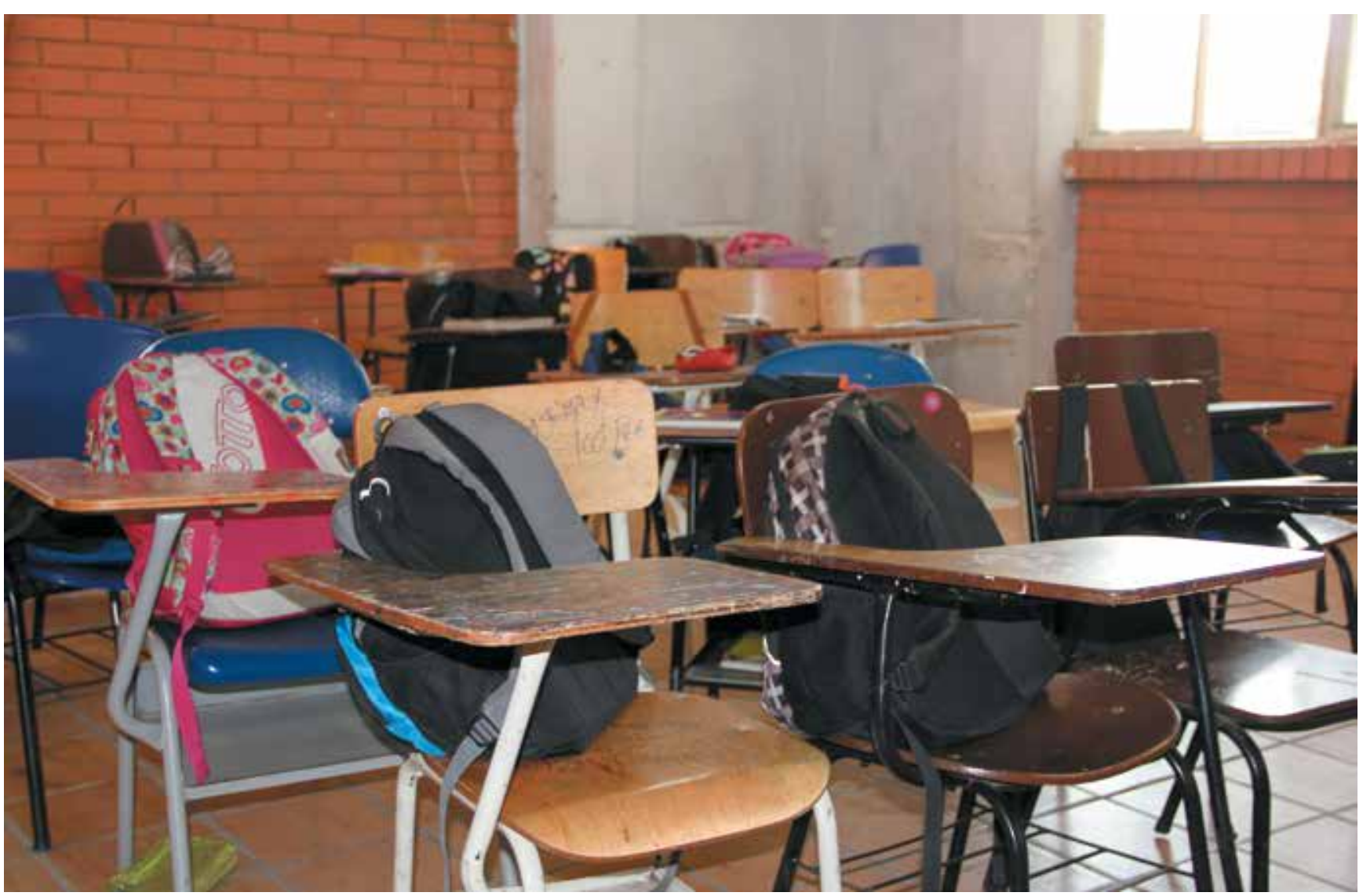

construyen los interlocutores. Desde esta mirada Levinas considera el lenguaje como un "trascendental empírico que, en cuanto proximidad y respuesta al otro, posibilita la relación ética" (1987). Concibe el lenguaje, en cuanto decir, como "posibilidad para la representación y el significado" (Levinas, 2002, p. 34), relación ética que origina con el otro una responsabilidad, una sustitución del sí mismo por el otro.

El giro del lenguaje hacia la hermenéutica es desde donde nos paramos para problematizar la mirada a la escuela y especialmente a los vínculos que establecen los sujetos que la habitan

Ahora bien, el ser humano desde que nace establece vínculos consigo mismo, con los otros -sociedad-y con lo otro -cultura- (Ramírez, 2005, p. 18). Este encuentro está mediado por intereses y deseos que llevan a los sujetos a dar cumplimiento a su propósito de vida; son los vínculos, configuradores de la subjetividad, los constructores del sujeto.
El diccionario define el concepto "vínculo" como "Unión o atadura de una persona o cosa con otra" (DRAE, 2009). Para nuestra indagación validamos el poder del lenguaje, desde la perspectiva pragmática, para la concreción del contacto de uno con otro y con lo otro; ya que el vínculo no es solo entre sujetos; es también con lo otro, el universo cultural que a manera de realidad formal determina el ser desde su pensar y actuar.

\section{Modelo comunicativo y construcción del sujeto}

En el presente estudio el lenguaje se toma desde una perspectiva pragmática, vista esta como una disciplina que "...toma el lenguaje tal y como se manifiesta, es decir, inmerso en una situación comunicativa concreta" (Escandell, 1993). Por lo anterior, los procesos de interacción humana, entendidos como dinámicas estructuradoras y estructurantes de la conciencia cultural, individual y social, se concretan a través del lenguaje, utilizando el medio de la co- 
municación. Cuando hablamos o escribimos nos proponemos hacer algo utilizando la comunicación. Cada enunciación presupone, para su realización, la existencia de un enunciador o locutor y de un interlocutor u oyente, quienes intercambian enunciados.

Desde la perspectiva y enfoque de Ramírez (2007, p. 37) se concibe la comunicación como"un acto de individualización del locutor, quien por su participación en el acto grupal es socializado y, a la vez, actúa dentro del proceso de culturización mediante su participación en visiones, perspectivas y prejuicios de los saberes sobre los mundos" (Ramírez, 2007). El locutor se individualiza en la medida que es el productor de las enunciaciones que concretan el acto interactivo con otro desde referentes culturales (lo otro). Es la interacción, con el otro y desde lo otro, la responsable de su triple dimensión subjetiva, intersubjetiva y objetiva, que se traduce en las voces del individuo, la sociedad y la cultura para estructurar el discurso.

Michael Bajtin, explica lo que es la interacción verbal y el pensamiento dialógico al considerar que

Todo signo resulta de un consenso entre individuos socialmente organizados en el transcurso de un proceso de interacción, razón por la cual las formas del signo están condicionadas tanto por la organización social de dichos individuos como por las condiciones bajo las cuales la interacción tiene lugar (1989, p. 67).

Plantea que se debe tomar como unidad de base y como estructura socio-ideológica la interacción, pues es la única realidad de la lengua; ni el sistema solo, ni el acto de creación individual pueden dar cuenta en forma satisfactoria de la realidad esencial del lenguaje, porque unos y otros se basan en la enunciación monológica aislada del contexto interaccional.

Según Bajtin la evolución real del lenguaje se da ya que

las relaciones sociales evolucionan en función de las infraestructuras, después la comunicación y la interacción verbal evolucionan en el marco de las relaciones sociales, las formas de los actos de habla evolucionan en razón de la interacción verbal, y el proceso de evolución es reflejo finalmente en el cambio de las formas de la lengua" (1989, p. 67).

Esta afirmación explica cómo se establece la relación del proceso social e individual. Cómo se relaciona lo subjetivo con lo objetivo, así como la movilidad del lenguaje: "la lengua vive y evoluciona históricamente en la comunicación verbal concreta, en la comunicación enmarcada en la vida cotidiana" (Bajtin, 1989). En esta concepción de lenguaje la enunciación es manifestación social, un encuentro entre lo social y lo individual.

En relación con el lenguaje como comunicación, Ramírez plantea una perspectiva de discurso que se desprende de la siguiente tesis:

...el mundo de saberes de los cuales cada uno de los comunicadores hace parte en diversas porciones, diversos grados de claridad y confusión forman un entramado de campos y marcos, algunos con límites más o menos precisos y otros definitivamente difusos, son voces con las cuales se arma su significación en los actos de comunicación. Voces recordadas e insertas en el discurso con la integralidad significante y como contenidos de delimitación de diverso orden (2007).

Más adelante agrega:

son voces, por lo tanto, que están constituidas como textos y discursos que son la base para la producción de los nuevos discursos. Son voces que se organizan en contenidos de los discursos procedentes de la cultura, de la sociedad y del individuo mismo. El texto señala la entrada para avanzar al análisis del discurso ya que este "mira el proceso de construcción de sentido" (2007).

La concepción polifónica del lenguaje en la que la enunciación es confluencia de voces de la cultura, la sociedad y del mismo sujeto, y resultado de las necesidades de expresar, interactuar y conocer; es el marco de referencia desde donde hacemos la presente disertación. 


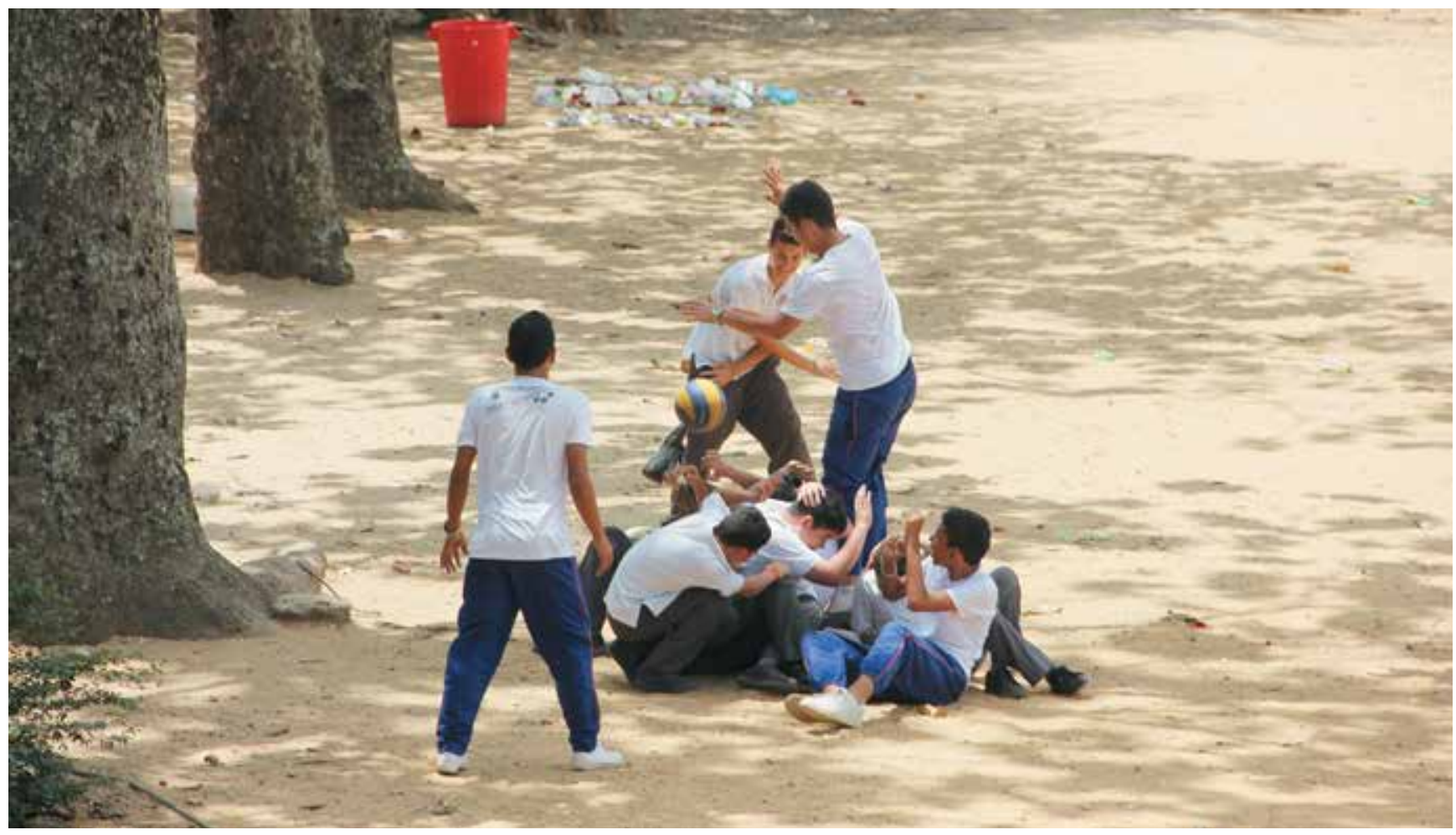

\section{Resultados: configuración del sujeto educativo: docente - estudiante}

En el apartado anterior pudimos observar que el sujeto, materializado en lo que dice y hace con su lenguaje, se construye desde el encuentro de voces de la cultura, la sociedad y su propia voz. El vínculo del sujeto con la sociedad y la cultura estará determinando su subjetividad. Para efecto de avanzar en la indagación por el vínculo configurador de la subjetividad del sujeto educativo que nos convoca, procederemos, desde historias de vida, tipo corpus textual, a describir proposiciones que develan marcas socioculturales que a manera de huella condicionan el actuar presente. La historia de vida es vista como discurso que se produce en determinadas condiciones y contextos y resultado de la confluencia de voces de la sociedad, la cultura y la propia voz del sujeto enunciador. A manera de apéndice relaciono la historia de vida de María Cabello que, así como otras veinticuatro más, sirvió como corpus textual para el análisis discursivo.

El estudio a las historias de vida arroja desde la discursivización cuatro categorías de análisis que intentan responder por la configuración de los sujetos educativos, especialmente por la configuración del sujeto docente, veamos:

\section{Vínculo trascendental y la escuela salvadora}

El reconocimiento de la existencia, presencia y dominancia de un ser superior que todo lo puede, lo sabe y lo determina genera en los sujetos educativos formas de pensar y actuar propias de la tradición mítico religiosa. El concepto "religión" "procede de religare que significa juntar, unir" (DRAE, 2009). El ámbito que caracteriza esta subjetividad es portador de un ideal que deja a la trascendentalidad la razón de su existir.

En las historias de vida se percibe un determinismo sociocultural que justifica la conciencia temporal (pasado, presente y futuro) desde la acción epistémica: "Así lo quiso Dios", "Dios proveerá" o "Dios sabe cómo hace sus cosas" son determinismos propios de una moral trascendental. El corpus objeto de análisis ofrece proposiciones ilustrativas, como: 


\section{Tabla 1. Historia de vida I}

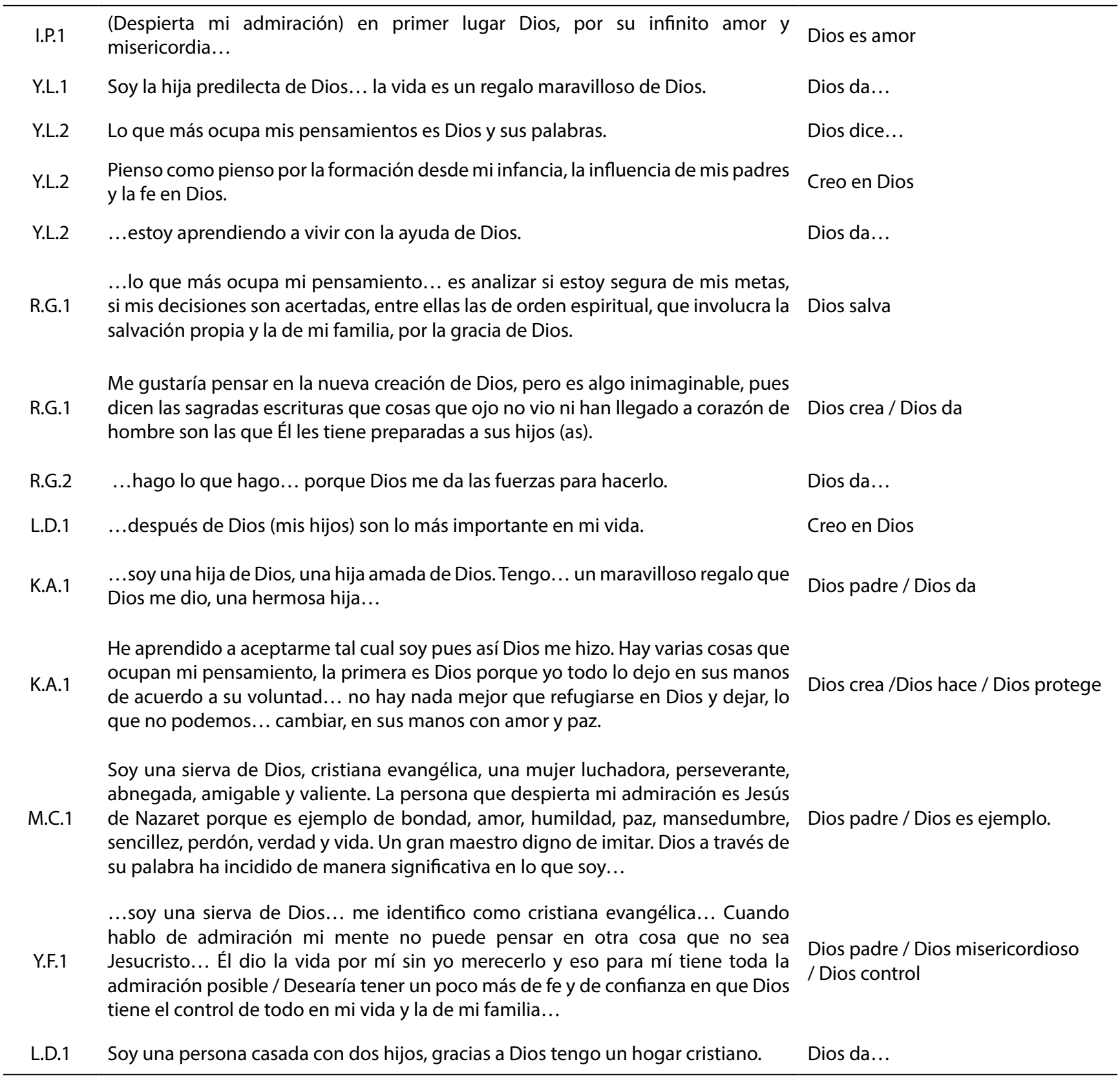

Fuente: autor.

El corpus devela la construcción simbólica que el sujeto docente hace sobre la divinidad: Dios padre, misericordioso, dador de vida, ejemplo a seguir, protector, Dios creador, salvador... y omnipotente. Es el dispositivo de control que habita en la "escuela salvadora", como la hemos nombrado en este estudio, y al que los sujetos educativos deben su-misión y obediencia, reviviendo así la escuela pre-moderna y confesional.

\section{Vínculo familiar y la escuela protectora}

El corpus objeto de indagación ubica el vínculo familiar como determinante de lo que soy (presente) y de lo que seré (futuro):"Mis padres me formaron así y así formo a mis hijos", "de tal palo, tal astilla", reza el dicho popular: 


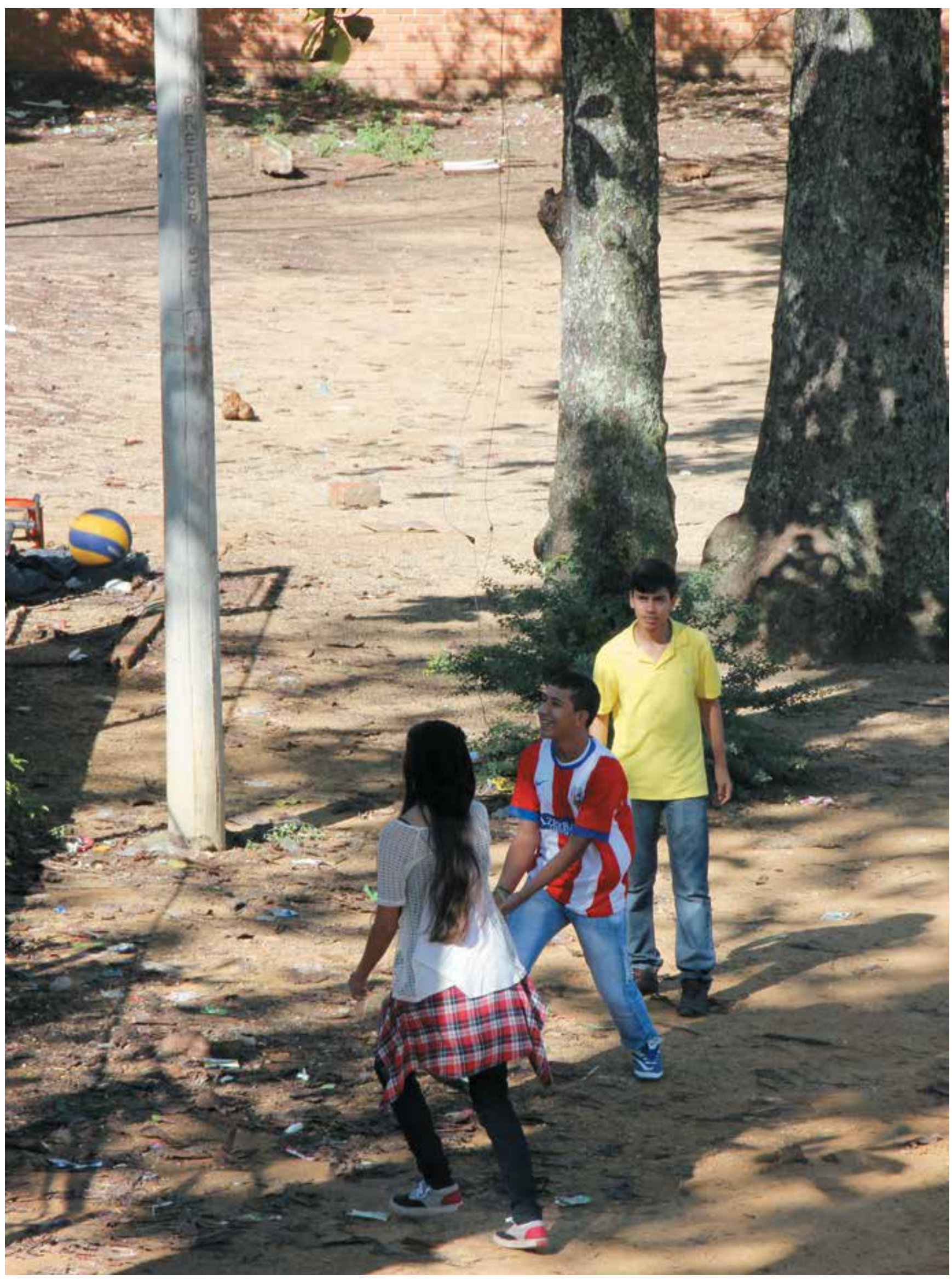




\section{Tabla 2. Historia de vida 2}

J.A.1 $\quad$...mi madre, el ser más importante en este planeta.

I.P.1 Toda mi vida he estado rodeada de educadores en mi entorno familiar.

I.P.1

...(despierta mi admiración) en segundo lugar mi madre quien ha sido mi ejemplo para seguir...

Su existencia (la de mi hijo) me ha impulsado a ser luchadora, optimista y querer estar cada vez mejor.

C.L.1

Admiro mucho a mi madre porque con tanto sacrificio... mantuvo ese carácter de padre y madre para poder formarnos con buenos principios...

Todo mi pensamiento lo ocupan mis hijos, ya que ellos son el tesoro más grande que

(C.L.2) tengo, aparte de mi madre que la quiero mucho, y que me ha dado su apoyo en los momentos más difíciles que he pasado.

(C.L.2) ...mejorar yo profesionalmente y también como persona para que en el futuro ellos (mis hijos) tengan una estabilidad...

R.G.1

...mi madre, aun con sus defectos... roba mi admiración... ella me ha motivado a ser lo que soy.

(M.J.I.1) …mi padre digno ejemplo de admiración...

M.J.I.1

...mi madre muchas veces pienso que es de acero, pero inoxidable; nunca se cansa, estando siempre dispuesta a ayudarme, siendo mi mayor apoyo en cada una de mis metas.

...despierta mi admiración... mi madre... nos ha levantado tanto a mi como a mis

S.C.1 hermanas y hoy en día su cosecha ha germinado... todos los logros que he obtenido, es gracias a (ella)... soy lo que soy por ella.

Desde pequeño me sentí muy orgulloso de mi mamá y mi papá... los admiro por su gran amor incondicional... Mi madre es quien ha incidido de manera significativa en lo que soy, debido a que cuando era pequeño veía el respeto de sus alumnos con ella y de los representantes también...

Hoy en día hay muchas cosas que ocupan mi pensamiento, pero creo que lo principal es mi hija...

(J.M.C.1

Mi madre es mi admiración, ella me ha formado para convivir en armonía, para amar y ser amado, para respetar y ser respetado.

(J.M.C.1)

La familia es el motivo de impulso y es el espejo que refleja lo que deseamos, sin ella no habría objetivo por alcanzar.

...(mi padre) ha incidido en buen porcentaje en lo que soy, agradezco profundamente todas sus orientaciones. Como docente soy como en mi rol de madre...

Me aterra pensar en que algún día mi pareja y yo nos separemos... no deseo ese momento para mí ni para mis hijos.

La razón por la cual pienso como pienso, es la formación que desde la infancia recibí

M.C.2 de mis padres, quienes siempre se han preocupado por enseñarme principios bíblicos, guiándome por el buen camino... y esto ha sido fundamental para mi formación personal.

Mi mamá fue mi primera maestra, me enseñó a leer y... a escribir. Mi mamá siempre me

E.B.1 cantó canciones y nunca dejó de cantármelas cuando era niña, todavía en mi casa se oyen esas canciones, porque con ellas arrullamos a los niños que ahora arrullan nuestro hogar.

Y.F.1

...me enorgullecía muchísimo la inspiración y la entrega de mi mamá para enseñarnos...

Eso me motivó mucho a ser como ella...

(L.M.B.1)

Esos valores de vida me los dio mi madre a quien admiro profundamente porque es un ser

dispuesto a dar amor siempre...

Referente para seguir

Referente familiar

Referente para seguir

Motivación familiar

Referente para seguir

Compromiso familiar

Compromiso familiar

Referente para seguir

Referente para seguir

Referente para seguir

Referente para seguir

Referente para seguir

Referente para seguir

Motivación familiar

Referente para seguir

Tradición familiar

Referente para seguir

Referente para seguir

Referente para seguir 
¿Qué efecto genera la preponderancia del referente "madre" en la configuración de la subjetividad docente? ¿Una sociedad donde la "madre" es el factor núcleo de la familia, transfiere este factor a la escuela? En nuestra sociedad y particularmente en la escuela, se despliega la concepción del maestro(a) protector(a), condescendiente, alcahueta. Así mismo, se muestra la escuela como el segundo hogar para los sujetos(as) educativos. Los padres naturales dejan a sus hijos al cuidado de los padres putativos (profesores) y estos últimos fundamentan un vínculo ya en el afecto, amistad, conocimiento o en su mezcla. Es característico -de la escuela que tenemos- que la interacción se fundamente en la familiaridad y protección, más que en la relación docente-estudiante o experto-novato. Predomina, entonces, una moral del cuidado por sobre una ética valorativa, concretándose lo que hemos dado en llamar la "escuela protectora".

\section{Vínculo social y la escuela intersubjetiva}

Tanto el vínculo trascendental como el familiar entran a jugar en el escenario del vínculo social; los sujetos son portadores de antifaces que lucen de acuerdo con las necesidades y oportunidades; es así como se hará gala del antifaz más pertinente para la ocasión que lo amerite.

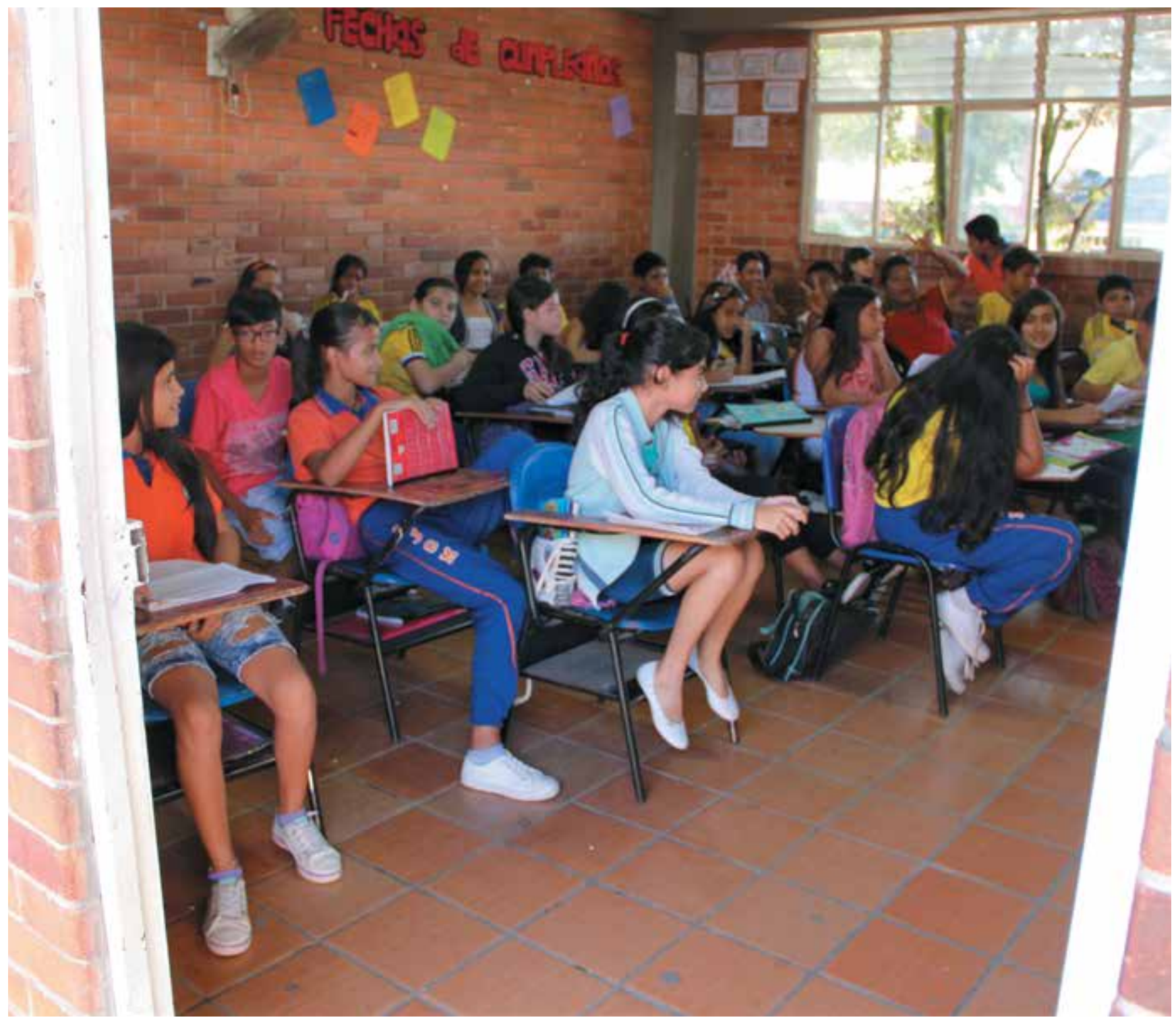




\section{Tabla 3. Historia de vida 3}

J.A.1 Desde niño siempre me ha gustado ayudar a los demás... tal vez por esto mi decisión de convertirme en educador.

J.A.2

No quisiera ser jamás un conformista... No... parecerme a un prototipo a un estúpido armazón, que camina por las calles sin ninguna dirección

Como educadora, además de impartir mis clases y ... compartir mis conocimientos...

I.P.2 también... sirvo de guía y los ayudo a resolver situaciones cotidianas de la vida, aconsejarlos y formarlos en valores y buenas costumbres, apoyarlos si enfrentan alguna dificultad, etc.

R.G.2 ...como consejera... trato de no ser injusta, pero es una tarea ardua.

No quisiera ser jamás una mala persona, una delincuente, una traidora, en fin, alguien dañino a la sociedad.

Me gustaría pensar en la ayuda que pueda darle a todos esos niños que pasan tantas

C.L.2 necesidades. ¿Por qué? Porque pienso en mis hijos, en mis sobrinos ya que ellos podrían estar en el mismo lugar.

M.J.I.2

...trato de dar lo mejor afianzándole a mis estudiantes valores primordialmente, como también el hábito de la lectura comprensiva y a las buenas acciones hacia el prójimo.

P.G.1 ...desde pequeño siempre me gustó enseñar a los demás...

...vivimos en un mundo injusto... en eso no quisiera pensar pero es lo que vemos a

J.M.C.1 diario... cuando veo el dolor ajeno... lo sufro porque ante los ojos de Dios todos somos iguales.

A.L.5 ...el profesor... despierta mi admiración por la preparación, conocimiento y muy buen lector, modelo por seguir.

N.R.4 mí.

L.D.1 Cuando estudiaba en la escuela había una persona que me decía que cuando fuera grande yo iba a ser maestra, y esto me motivaba más a seguir con mi decisión de ser educadora...

H.D.1

...lo mágico que es ser docente, siendo importante decir que esa magia me la transmitieron mis profesores.

H.D.3 El mundo actual tiene una dinámica de quítate tú para ponerme yo.

M.C.3 ...la generosidad y la solidaridad son elementos esenciales para la vida en sociedad.

L.M.B1 ‥en mi infancia jugaba a ser maestra.

Y.F.3 …mi propósito en este mundo es amar y servir a mi prójimo.

...pienso que hay un niño huérfano sin padres esperando por mí para complementarnos E.B.5 en el amor, en el cuidado y en el crecimiento mutuo.
Solidaridad

Actitud crítica

Referente humano

Justicia

Referente humano

Solidaridad

Referente humano

Solidaridad

Justicia

Referente modelador

Docente modelo

Referente modelador

Referente modelador

Desplazamiento

Generosidad y solidaridad

Deseo

Espíritu de servicio

Espíritu de servicio

Fuente: autor.

En las anteriores proposiciones se observa que el contexto y la acción discursiva del interlocutor condicionan al locutor; se habla como el otro quiere escuchar. Desde esta perspectiva se devela una subjetividad mati- zada por el predominio del deber ser y las valencias acordadas y aprobadas por el universo socio-cultural del momento. La influencia del vecino, el peso de la tradición, el ascetismo y el dominio de la moral son los impulsos 
determinantes de la configuración del sujeto constructor de la escuela intersubjetiva.

\section{Vínculo existencial y la escuela crítica}

El corpus, y su propósito de develar la "conciencia de sí", busca que el docente en su na- rrativa se comprenda, entendiendo este comprender como la acción reflexiva orientada a la construcción de una subjetividad autónoma que permita el acto de transformación consciente.

\section{Tabla 4. Historia de vida 4}

J.A.3 Trabajo (en la docencia) para sobrevivir y hago música para poder existir

S.C.3 ...soy una persona que cumplo con el deber ser...

...considero que la educación es parte primordial de la vida, sea cual sea la especialidad que se enseñe.

...me aferro... en buscar trascender lo establecido, romper las barreras que obstruyen el avance de la humanidad. No comulgo con muchas de las "normas" sociales establecidas, pues durante la historia se han empleado para subyugar a los más débiles y empoderar... a los poderosos.

...soy un profesional que lucha por lo que quiere y que espiritualmente se siente bien consigo mismo, debido a que disfruta lo que hace porque ama su profesión. Cada día debemos ser mejor persona.

A.L.7 ...quisiera ser libre, decir lo que quiero... pero no puedo.

H.D.2 ...me parece ilógico que hayamos nacido solo para hacer las cosas comunes.

H.D.3 ¿De qué sirve vivir, si pasamos sin dejar huella?

M.C.3 ...no existe nada mejor que tener la libertad de poder sentirte bien con lo que haces.

....pareciera que ser educador significa ser un modelo... Esa doble moral con la que se ha dispuesto formar a los docentes me aburre... pues... somos seres como los demás con defectos y virtudes... / ...estoy... procurando mostrarle (a los maestros (as)) que son seres que aman que quieren, desean y hasta tienen malos pensamientos...

...soy una mujer que quiero y pretendo vivir mi vida, recorrer mi camino, a pesar de que esto me lleva a vivir contracorriente, siempre soñando, siempre emprendiendo empresas complicadas. No quiero quedarme sentada esperando que la vida me pase, si no que quiero construir lo que soy de la mano con mis creencias y con mis valores de vida.

Lo que más ocupa mi pensamiento es quedarme varada en la vida, no lograr lo que quiero... no descubrir a estas alturas que me quede esperando que la vida pasará y no cumplir mis sueños... /...espero que mis alumnos no sean unas hojas al viento, busco confrontarlos con experiencias que los hagan vibrar, pensar, ver otras posibilidades... /... me encuentro revisándome, pensando y caminando hacia mi propio encuentro. Me estoy repensando para dar una real vuelta y mirar distinto, de cara al viento.
Ser

Deber ser

Fundamento de vida

Cultura de la resistencia

Convicción

Libertad como deseo

Inconformidad

Inconformidad

Ser

Ser en libertad

Libertad como propósito de vida

Mirar hacia dentro para comprender el afuera.

Fuente: autor.

Según Castoriadis en la subjetividad reflexiva el sujeto es capaz de cuestionar las significaciones imaginarias de la sociedad en la que vive, e incluso, sus instituciones, a partir de una "subje- tividad autónoma, caracterizada porque el sujeto no está arrastrado por el inconsciente, sino que es capaz de ser lúcido en relación con sus deseos, de conectarse y ser permeable a ellos, y 
de poder, al mismo tiempo, filtrarlos" (1989). Es un sujeto reflexivo y autónomo, que actúa en consecuencia.

\section{Conclusiones}

La realización del presente artículo ha permitido dar cumplimiento al propósito de comprender la incidencia del lenguaje, y del vínculo que a través de él se establece, en la configuración subjetiva de los sujetos educativos. Esto mediante la interpretación de $\mathbf{2 8}$ historias de vida de docentes que ofician su magisterio en instituciones educativas del Oriente venezolano.

Esta reflexión, integral por sus alcances, se hace desde un texto que se interpreta para buscar un sistema de categorías que oriente la comprensión de la acción cultural e histórica del vínculo social en la configuración de los sujetos educativos.

Entiéndase por subjetividad la construcción que hace el sujeto en su interacción con la sociedad y la cultura, traduciéndose esta en las necesidades y deseos que determinan su pensar, sentir y actuar. Como lo dijera Claudia Zichero, "la subjetividad es la manera en que cada sujeto emerge, se sobrepone y se construye en las diferentes coyunturas históricas" (2012). Proceso que se concreta en sus dinámicas constituyentes; aquellas en que el sujeto se piensa, se narra, se conoce, se observa, se interpreta, se transforma, se da su propio ser, lo que permite transitar de lo constituido a lo constituyente.

El resultado de esta indagación, con pretensiones comprensivas, es que así como hay un vínculo configurador, hay otro configurante de la subjetividad; el primero me construye como sujeto y el segundo me posiciona como configurador de subjetividades. Todo proceso de discursivización cumple esa doble función, siendo el acto de interacción el escenario generador del sujeto discursivo; es decir, así como construimos, somos construidos.
Se observa que el vínculo prefigurador de una subjetividad trascendental construirá sujetos dependientes del poder externo y divino. Desde esta concepción se construye una escuela salvadora que ofrece un espacio escolar donde se puede limpiar el cuerpo y salvar el alma. La escuela se convierte en el templo que borra el pecado siempre y cuando el feligrés (estudiante) obedezca al sacerdote (docente), entablándose relaciones de dominación y sumisión: docente alumno, amo - esclavo, sabio - ignorante.

Un vínculo familiar, dijimos, construye la "escuela protectora", condicionando su propósito educativo al cuidado físico y moral del otro. El sujeto reclamará en su estudiante el comportamiento propio del buen hijo; de no encontrarlo, este corre el riesgo de ser desheredado.

El vínculo social ubica al sujeto como miembro del colectivo o como preservador del tejido social que fortalece la intersubjetividad. Así mismo, un vínculo existencial, fundador de la escuela crítica, evidenciará la búsqueda permanente, obsesiva y algunas veces neurótica del sujeto que se construye. Desde esta perspectiva, al igual que en el vínculo social, el fundamento es la intersubjetividad. Aquí se ve al otro desde su capacidad y debilidad humana, reconociéndole su carácter histórico, abierto y dialéctico; como un igual con el que se dialoga. El otro no es Dios ni es la madre; es otro con el que me encuentro en el diálogo, la confrontación y la disputa para avanzar en la construcción que define al ser desde un pensar y un actuar con el otro (sociedad) y lo otro (cultura). Son estos vínculos los constructores de una escuela contemporánea, viva y abierta a lo posible; una escuela donde se experimenta la vivencia, que invita y anima a la libertad.

Es entonces el tipo de vínculo, que la impronta discursiva activa en su configuración, la que definirá el tipo de sujeto educativo que habitará nuestras escuelas.

Apéndice: Historia de vida de María Cabello 


\section{M.C. 1}

2 Mi historia personal.

De niña qui muy traviesa siempre andaba inuentando juegos e historias maravillosas, recuerdo que me gustaba visitar la biblisteca, milugar favorito era la sala de lectura infantil, donde pasaba horas y horas leyendo cuentos entre ellos: Blancanieves, la Cenicienta, la bella durmiente, pinocho, los tres cochinitos y otros. Ja lectura de esos textos despertaba mi imaginación tanto que me sentía como parte del relato recreando'Cada escena. Cuando me reunía Con mis compañeritos les Contaba esas historias, ellos presta. ban mucha atención y me hacían preguntas yo les respondía y también les preguntaba, así pasabamos el tiempo Conversando, riéndon os e inventando cuentos, pienso que esas experiencias incidieron en mi decisión de ser docente. - Sor una sierva de Dios, Cristiana evangélica, una mut $10^{2}$ La persona que despierta mi admiración es Jesús de Nazaret porque es ejemplo de bondad, amor, humildad, paz, mansedumbre, sencillez, perdón verdad y vida. Un gran maestro digno de imitar. Diariamente hago mi mayor esfuerzo por no ser una persona egoista, envidiosa, deshonesta, mentirosa, hipócrita y Chismosa, porque Considero que son antivalores que contaminaw el espiritu y no nos permiten estar en comunión con el Se $\vec{n}$ or, ni con nuestros semejantes, es mejor Conservar y llevar a la práctica los valores y principios que nos han enseñado para tener éxito en nusstras relaciones interpersonales. Dios a través de su palabra ha incidido de manera significativa en 10 que soy, mis padres, familiares, hermanos en la fe, $y$ mis profesores. 


\section{M.C.2}

In cada situación que me ha tocado vivir viene a mi mente un pasaje biblico', pienso muchó en cómo será la vida eterna y el lugar celestial que Dios nos fue a preparar. Tambien pienso en mis estudios y todos los trabajos que me faltan por presentar entre llos: la tesis.

Me gustaría en Cómó es el infierno, pero no puedo, por que de solo imaginar ese lugar tan horroroso, digo' no; la vida is muy bella y yo como' hija de Dios habitaré para siempre en el paraís.

No me gustaría pensar en la maldad, el pecado, los deseos de la carne y la vana gloria de la vida, pero por mi naturaleza humana, en ocasiones, no resisto la tentación y peco.

La razón por la cual piensó comó pienso, es la formación que des de la in ancia recibi de mis padres quienes siempre se han preocupado por enseñarme, principios biblicos, guiandome por el buen camino y eso me ha permitido'ser mejor persona. hija, hermana, estudiante y profesional y esto ha sido funda. mental para misuperación personal.

Como educadora me siento comprometida con mi labor, Considero que educar es un gran reto, pero con vocación y de dicación hoexisten limitantes para ejercer tan honorable profesión, por esa razón me agrada estar en Constante preparación, es. tudiando, investigando, analizando e inter pretando acerca del quehacer cotidiano, en mi opinión es de suma importancia el proceso de formación docente, la actualización yla creatividadien el acto de enseñar.

Como hija trato de comportarme de la mejor manera, res. petando la memoria de mi padre, ayudando a mi madre en lo que puedo, doy consejos y lucho por ser ejemplo para mis hermanas. 
ÍTACA: ARTÍCULOS DE INVESTIGACIÓN E INNOVACIÓN

91

M.C.3.

Como Compañera de clases me gusta compartio con los demás y brindar a poyo' a quiew do necesite para mú, la generosidad y la solidaridad son elementos esenciales para la vida en sociedad.

Qrisiera hacer una gira por el continente Europeo y los países que me gustaria visitar serían España y Frant lia, Suno con caminar las Calles de Madrid, París no tengo los recursos financieros para realizar ese viaje.

No quisiera pensar en la crisis, que actualmente atraviesa el país, peró tengo que hacerb, porque Como venezolana debo conocer la realidad que me rodea, para enfrentar el día a día y adaptarme a los cambios con seriedad y responsabilidad.

Hago lo que hago", porque me gusta, porque dis jruto en hacer lo que quiero sin complicaciones, ni prejuciosy no existe nada mejor que tener la libertad de poder senterte bien con to que haces.

Prof(a): Maria Cabello. C.J. 75.876 .055 .

Curso: Análisis del descurso. Profesor: Fairo Acerdo Leal. 


\section{Referencias bibliográficas}

Abbagnano, N. (1995). Diccionario de filosofia. México: Fondo de Cultura Económica.

Bajtin, M. (1989). Teoria y estética de la novela. Madrid: Taurus.

Castoriadis, C. (1989). La institucion imaginaria de la sociedad. Barcelona: Tusquets.

Derrida, J. (1986). La gramatología. México: Siglo XXI.

DRAE (2009). Bogotá: Imprenta Patriotica del Instituto Caro y Cuervo.

Escandell, V. (3 de 12 de 1993). www.es.scribd.com. Recuperado el 18 de junio de 2013 de http://es.scribd. com/doc/51664312/Modelo-de-analisis-pragmatico-de-la-comunicación-de-Maria-Victoria-EscandellVidal.

Gadamer, H. (1973). Philosophical hermeneutics. Los Ángeles: Universidad de California.

Ingenieros, J. (2000). El hombre mediocre. Buenos Aires: El Aleph.
Levinas, E. (1987). De otro modo que ser o más allá de la esencia. Salamanca: Sígueme S. A.

Levinas, E. (2002). Totalidad e infinito. Salamanca: Sígueme.

Pabón, G. (1998). El maestro en cuentos. Bogotá: Letra Escarlata.

Palacio, M. (2013). La posición de Levinas en el giro hermenéutico. Areté, 133 -152.

Ramírez, L. (2004). Discurso y lenguaje en la educación y la pedgogía. Bogotá: Cooperativa Editorial Magisterio, coleccion Seminarium.

Ramírez, L. (2005). Estudios del discurso en Colombia. Medellin: Unimedellin.

Ramírez, L. (2007). Comunicación y discurso. Bogotá: Cooperativa Editorial Magisterio.

Ricoeur, P. (2008). Sí mismo como otro. México: Siglo XXI.

Zichero, C. (s.f). Aprendizaje y subjetividad. Recuperado de http://www.docentesdeizquierda.com.ar/zichero. htm. [Consulta: 2012, febrero 4]. 